\title{
Optimal Ordering Strategy for Goods at Multiple Retail Prices under Simultaneous Sales
}

\author{
Yunzhi Mu $\mathbb{D},{ }^{1,2}$ Zhiqing Meng $\mathbb{D},{ }^{1}$ Rui Shen $\mathbb{D},{ }^{3}$ Gengui Zhou $\mathbb{D},{ }^{1}$ \\ Leiyan $\mathrm{Xu}(\mathbb{D})^{1,4}$ and Minchao Zheng $\mathbb{D}^{1}$ \\ ${ }^{1}$ School of Management, Zhejiang University of Technology, Hangzhou, Zhejiang 310023, China \\ ${ }^{2}$ Keyi College of Zhejiang Sci-Tech University, Shaoxing, Zhejiang 312369, China \\ ${ }^{3}$ School of Economics, Zhejiang University of Technology, Hangzhou, Zhejiang 310023, China \\ ${ }^{4}$ Zhejiang University of Finance and Economics, Xiasha, Hangzhou 310018, China
}

Correspondence should be addressed to Zhiqing Meng; mengzhiqing@zjut.edu.cn

Received 6 March 2019; Revised 27 June 2019; Accepted 8 July 2019; Published 18 July 2019

Academic Editor: Emilio Jiménez Macías

Copyright (C) 2019 Yunzhi Mu et al. This is an open access article distributed under the Creative Commons Attribution License, which permits unrestricted use, distribution, and reproduction in any medium, provided the original work is properly cited.

To stimulate purchases from consumers, retailers nowadays use the multiple retail prices strategy (MRPS), i.e., selling the products at multiple prices simultaneously. The paper extends the current newsboy model and proposes an optimal ordering model for MRPS corresponding to uncertain consumer demands. The Lagrangian multiplier method is applied to solve the problem, and an algorithm for finding the approximate optimal total order quantity is designed. Numerical results show that MRPS is better than the single retail price strategy (SRPS). It further reveals that when there is an order quantity constraint, the retailer needs to control the number of retail prices; that is, retailer's MRPS is affected by order quantity constraint; sensitivity analysis demonstrates that MRPS is also affected by the price discount coefficient in the case of no order quantity constraint while it is not affected by demand volatility. The research work provides some useful managerial inspirations for retailers.

\section{Introduction}

The multiple retail prices sales are widely used in practice. Consumers often find that the same product is sold at multiple retail prices simultaneously online or offline, a promotional strategy of retailers. For example, food, daily necessities, cosmetics, health products, office supplies, clothing, books, and others are sold simultaneously but at different retail prices on platforms like Tmall.com, JD.com, Dangtang.com, and Amazon.com, and even in the same sales outlet, products like Starbucks coffee, McDonald's ice cream cones, and shared massage chairs are also sold at multiple retail prices. Examples are found in Table 1. It has been proved by practices that MRPS can effectively increase retailers' sales volume and profits as compared to SRPS.

Most MRPS researches are concerned with the effects of MRPS on consumer behavior. Some have demonstrated that MRPS often results in greater sales volume relative to SRPS [1-4]. There are other research papers covering the consumers' purchasing intention under MRPS $[5,6]$ and the effects of consumers' perceptions towards MRPS [7]. However the studies focused only on the empirical assessment of the effectiveness of MRPS from the perspective of marketing and consumer behavior.

There are also several mathematical models concerning MRPS, but the focus is not on ordering decision with MRPS; e.g., Thomas and Chrystal (2013) [8] and Kim et al. (2016) [9] studied MRPS focusing on relative utility pricing model and dynamic pricing, respectively; Bazargan et al. (2018) [10] and Bazargan et al. (2019) [11] used game theoretic approach to evaluate the profitability of 'buy $\mathrm{n}$ times, get one free' loyalty programs; and Rahimi et al. (2019) [12] applied a mixed integer nonlinear programming to design a sustainable supply chain network.

Khouja (1999) [13] and Qin et al. (2011) [14] reviewed many newsboy models about SRPS ordering strategies. Therefore, the obtained ordering strategies of SRPS are not suitable for the ordering problem of MRPS provided by retailers. To the best of our knowledge, it is very common for retailers to provide MRPS. Retailers who apply MRPS 


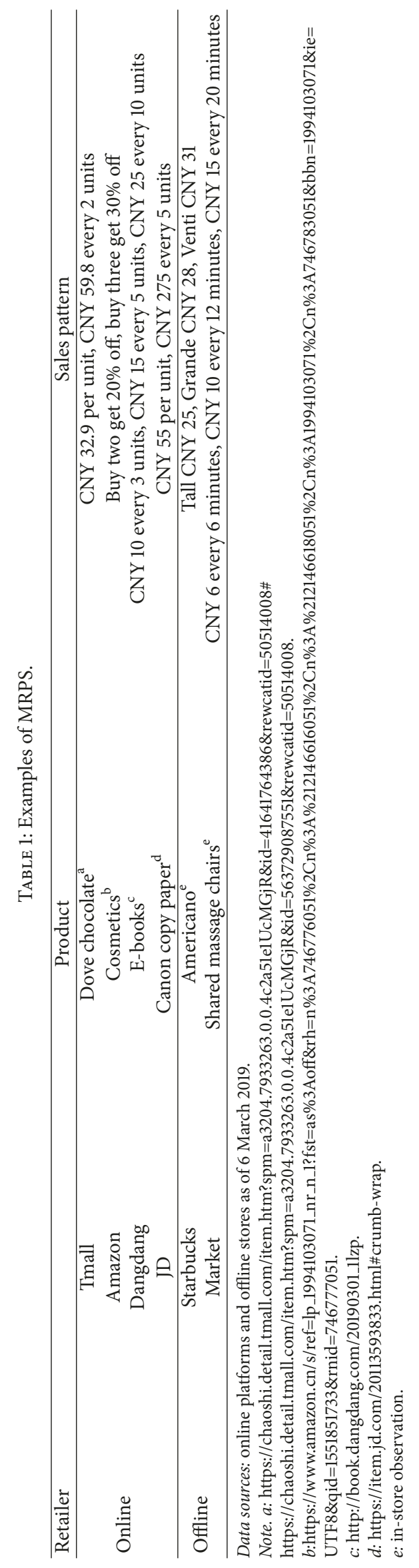


can always see an increase in the order quantity due to increasing demand and can obtain more consumer surplus [15]. Currently, the studies on MRPS of retailers focus on the different retail prices at different sales stages to handle excess inventory [16-18] instead of handling it simultaneously. Therefore motivated by this research gap, the present work attempts to establish an optimal ordering model for retailers providing simultaneous MRPS.

The contributions of this paper include the following: (1) the research is a beneficial supplement to the extant literature on MRPS of retailers and ordering decision problem; (2) we take the uncertainty in consumer demand into consideration, and based on expected profit maximization, we give the retailer simultaneous MRPS ordering strategy by establishing an extended newsboy model; (3) a solution algorithm, namely, the MRPS algorithm, is given to obtain the approximate optimal total order quantity of the retailer; (4) the paper solves the ordering problem of MRPS from the two perspectives, with and without order quantity constraint, compares the corresponding results, and derives insights to support the retailer's optimal ordering decisions.

The rest of the paper is organized as follows. Section 2 summarizes the relevant representative studies. Section 3 presents a single-period single-product inventory model with MRPS and order quantity constraint based on the classical newsboy model. After that, some properties of the model are analyzed. Section 4 develops the MRPS algorithm to solve the model and Section 5 gives numerical results. Finally, Section 6 discusses some managerial insights and gives further areas for study.

\section{Literature Review}

As an important branch of revenue management, MRPS has been widely applied by retailers. At present, researches on ordering decision under MRPS fall into SRPS and MRPS of retailers, where the ordering decision of SRPS is seen as a special case of MRPS, because there is only one retail price in the SRPS.

\subsection{Ordering Problem for SRPS. Relevant representative stud-} ies on SRPS can be found in literature [19-27], where the ordering decision of retailers selling products to customers at a single price is to minimize cost and/or maximize profit and the quantity discounts provided by suppliers include allunits discount, incremental discount, and other discounts. For example, Chen \& Ho [19, 20] focused on incremental quantity discounts and all-units discounts, respectively, to find the optimal order quantity for the single-order newsboy problem and minimize the total cost when the demand is fuzzy, while Chung et al. (2015) [21] studied markdown price by the supplier to determine optimal retail prices and order quantity to maximize the total expected profits. Taleizadeh et al. (2015) [22] proposed EOQ models with incremental discounts and Wang et al. (2019) [23] considered the optimal procurement strategies with all-units discounts; however, the ordering problem was solved from the perspective of backordering and lost-sales, respectively.
In addition, many studies of SRPS took constraint condition into consideration to make the ordering strategy more realistic [24-27]. Different constraints like budget constraint [24], production volume limits [25], and minimum-order quantity $[26,27]$ were considered. The above-mentioned studies focused mainly on the influence of quantity discounts provided by suppliers on the optimal ordering strategy of retailers and thus are not applicable to retailers' ordering problem under MRPS (multiple prices provided by retailers).

2.2. Ordering Problem for MRPS. In the real business world, it is common for retailers to apply MRPS, but under the order quantity constraint. To the best of our knowledge, the extant literature mainly focuses on the ordering problem when multiple prices discounts are used to handle excess inventory. Relevant representative studies can be found in literature [16-18, 28-31].

In such studies, with the purpose of maximizing the expected profit/revenue, newsboy problem is extended to the situations when different retail prices are used to handle excess inventory. Khouja [28-30] extended newsboy problem in which multiple prices discounts are used progressively to sell excess inventory. Recently, using newsvendor framework, Avittathur and Biswas (2017) [16] modeled the limited clearance sale inventory problem for determining the optimal order quantity, which was later extended by Biswas and Avittathur (2018) [17] to determine the optimal pricing and ordering decision.

However, the above studies do not take the constraints of the retailer into account, which is not a clear profile of the real world. There is rich literature discussing budget constraint, capacity constraint, etc.; for instance, many dealt with a multi-item newsboy problem with either a budget constraint or capacity constraint [32-34]. Constraints are to be taken into consideration just to make the ordering strategy more realistic, which in essence are the order quantity constraints. However, the studies do not consider MRPS of the retailer, which provides this paper the ideas of solving the retailer ordering problems under MRPS with the order quantity constraint.

Fortunately, there are a few researches on MRPS of retailers with constraints. For instance, Khouja and Mehrez [31] proposed a multiproduct newsboy problem to sell excess inventory through multiple discounts under a storage or budget constraint. They provided an efficient algorithm to solve the model. Further, excess inventory can be handled not only with multiple prices discounts, but also with upgrades or a combination method, and the newsboy problem was solved accordingly with a storage or budget constraint [18].

In the real world, MRPS is an alternative price strategy for retailers to maximize profit. Therefore, studying the optimal ordering decisions for retailers using MRPS is of fundamental significance. However, after considerable efforts on literature searching and sorting, a few researches are found in this respect when the products are sold at multiple prices simultaneously. Lu et al. (2014) [35] studied a dual-pricing strategy over a planning horizon and presented a joint analysis on quantity-based price differentiation and inventory control 
under a utility-based demand framework to maximize total expected profit. However it considered only two prices and did not take order quantity constraint into consideration. Consequently, we are to take the order quantity constraint into consideration, study a general MRPS scheme (the product is sold simultaneously at $n$ different retail prices by the retailer), and propose an optimal ordering model for MRPS to obtain an optimal ordering strategy for the retailer.

\section{Proposed Optimal Ordering Model for MRPS}

Based on the different consumers' tolerance to prices, retailers adopt MRPS to attract potential consumers and increase sales. In this paper, it is assumed that there is a retailer who offers one product to customers over a finite horizon of time using MRPS. In other words, the retailer sells the product simultaneously at $n$ different quantity-discount prices. $p=$ $\left(p_{1}, p_{2}, \cdots, p_{n}\right)$ is the price vector. Assume $p_{i}=(1-(i-$ 1)d) $p_{1}$, where $i=1,2, \cdots, n, d$ is the discount coefficient, and $p_{i}$ is the unit retail price when $i$ units are sold at the same time (i.e., $p_{1}$ is the normal retail price of the product), so the prices are strictly monotonically decreasing under the condition of $0<d<1$, i.e., $p_{1}>p_{2}>\cdots>p_{n}$. Let $\xi$ denote the demand of the product; $\xi$ is a random variable with unknown distribution. Let $f(\xi)$ and $F(\xi)$ be the marginal probability density function (pdf) and the marginal cumulative distribution function (cdf) of $\xi$, respectively. $\alpha_{i}$ is defined as the ratio of the demand under $p_{i}$ in the total demand (called demand ratio), where $\sum_{i=1}^{n} \alpha_{i}=1, \alpha_{i}>0$. Therefore $\alpha_{i} \xi$ represents the demand for the product under $p_{i}$. Table 2 provides an example of $\alpha_{i}$, where Retailer A sells one product at three different retail prices simultaneously: $p=(10,9,8)$, which means the normal retail price (i.e., no discount), "buy two get $10 \%$ off", and "buy three get $20 \%$ off", respectively. The sales volume in Table 2 gives the historic sales of Retailer A at each retail price, based on which demand ratios are calculated; e.g., demand ratio $\alpha_{1}$ when $p_{1}=10$ is $40 /(40+70+90)=0.2$.

Assume that the retailer is risk-neutral and its goal is to maximize the expected profit through the optimal total order quantity. The order quantity $q_{i}$ corresponding to $p_{i}$ is a decision variable; then the total order quantity is $\sum_{i=1}^{n} q_{i}$. The retailer decides the total order quantity at the beginning of the sales period at the unit ordering $\operatorname{cost} c$, which is less than $p_{i}$, as otherwise there is a loss before the sales. When a stock-out occurs during the sales period, there will be losses from shortages; $s_{i}$ is the shortage cost of per unit product when the product is sold at the price of $p_{i}$. After the end of the sales period, if there is any surplus, it might be disposed at the unit price $p_{h}$ which is either a very low price less than $c$ or a disposal cost.

Based on the classic newsboy model, the retailer's profit then is formulated as

$$
\begin{aligned}
\pi(\boldsymbol{q}, \xi)= & \sum_{i=1}^{n}\left(p_{i}-c\right) \min \left(\alpha_{i} \xi, q_{i}\right) \\
& -\sum_{i=1}^{n}\left(c-p_{h}\right)\left(q_{i}-\alpha_{i} \xi\right)^{+}-\sum_{i=1}^{n} s_{i}\left(\alpha_{i} \xi-q_{i}\right)^{+} .
\end{aligned}
$$

TABLE 2: An example of demand ratio $\alpha_{i}$.

\begin{tabular}{lcc}
\hline Retail Price & Sales Volume & Demand Ratio \\
\hline 10 & 40 & 0.2 \\
9 & 70 & 0.35 \\
8 & 90 & 0.45 \\
\hline
\end{tabular}

In (1), $\boldsymbol{q}=\left(q_{1}, q_{2}, \ldots, q_{n}\right)$ is the vector of order quantities, the first term is the net sales revenue of the product, the second is the loss due to excessive orders, and the last is the penalty cost for the shortage.

The retailer's expected profit is written as

$$
\begin{aligned}
& E[\pi(\boldsymbol{q}, \xi)]=E\left[\sum_{i=1}^{n}\left(p_{i}-c\right) \min \left(\alpha_{i} \xi, q_{i}\right)\right. \\
& \left.\quad-\sum_{i=1}^{n}\left(c-p_{h}\right)\left(q_{i}-\alpha_{i} \xi\right)^{+}-\sum_{i=1}^{n} s_{i}\left(\alpha_{i} \xi-q_{i}\right)^{+}\right] \\
& \quad=\sum_{i=1}^{n}\left[\left(p_{i}+s_{i}\right) \int_{q_{i} / \alpha_{i}}^{\infty} q_{i} f(\xi) d \xi-s_{i} \int_{q_{i} / \alpha_{i}}^{\infty} \alpha_{i} \xi f(\xi) d \xi\right. \\
& \quad+\left(p_{i}-p_{h}\right) \int_{0}^{q_{i} / \alpha_{i}} \alpha_{i} \xi f(\xi) d \xi+p_{h} \int_{0}^{q_{i} / \alpha_{i}} q_{i} f(\xi) d \xi \\
& \left.-c q_{i}\right] .
\end{aligned}
$$

It is easy to verify that the expected profit of retailer $E[\pi(\boldsymbol{q}, \xi)]$ is continuous in $q_{i}$, and then the concavity of $E[\pi(\boldsymbol{q}, \xi)]$ is proved in Lemma 1 .

Lemma 1. The expected profit of retailer $E[\pi(\boldsymbol{q}, \xi)]$ is strictly concave in $q_{i}$ for each $i=1,2, \ldots, n$.

Proof. From (2), it is clear that the expected profit under $p_{i}$ is

$$
\begin{aligned}
E\left[\pi_{i}\left(q_{i}\right)\right]= & \left(p_{i}+s_{i}\right) \int_{q_{i} / \alpha_{i}}^{\infty} q_{i} f(\xi) d \xi \\
& -s_{i} \int_{q_{i} / \alpha_{i}}^{\infty} \alpha_{i} \xi f(\xi) d \xi \\
& +\left(p_{i}-p_{h}\right) \int_{0}^{q_{i} / \alpha_{i}} \alpha_{i} \xi f(\xi) d \xi \\
& \left.+p_{h} \int_{0}^{q_{i} / \alpha_{i}} q_{i} f(\xi) d \xi-c q_{i}\right] .
\end{aligned}
$$

The first derivative of (2), with respect to (w.r.t.) $q_{i}$, is

$$
\begin{aligned}
\frac{\partial \mathrm{E}[\pi(\boldsymbol{q}, \xi)]}{\partial q_{i}} & =\frac{\partial \mathrm{E}\left[\pi_{i}\left(q_{i}\right)\right]}{\partial q_{i}} \\
& =\left(p_{i}+s_{i}\right)\left[\int_{q_{i} / \alpha_{i}}^{\infty} f(\xi) d \xi-\frac{q_{i}}{\alpha_{i}} f\left(\frac{q_{i}}{\alpha_{i}}\right)\right]
\end{aligned}
$$




$$
\begin{aligned}
& +s_{i} \frac{q_{i}}{\alpha_{i}} f\left(\frac{q_{i}}{\alpha_{i}}\right)+\left(p_{i}-p_{h}\right) \frac{q_{i}}{\alpha_{i}} f\left(\frac{q_{i}}{\alpha_{i}}\right) \\
& +p_{h}\left[\int_{0}^{q_{i} / \alpha_{i}} f(\xi) d \xi+\frac{q_{i}}{\alpha_{i}} f\left(\frac{q_{i}}{\alpha_{i}}\right)\right] \\
& -c \\
& =p_{i}+s_{i}-c \\
& -\left(p_{i}+s_{i}-p_{h}\right) \int_{0}^{q_{i} / \alpha_{i}} f(\xi) d \xi .
\end{aligned}
$$

Technically, the concavity is checked:

$$
\begin{aligned}
\frac{\partial^{2} \mathrm{E}[\pi(\boldsymbol{q}, \xi)]}{\partial q_{i}^{2}} & =\frac{\partial^{2} \mathrm{E}\left[\pi_{i}\left(q_{i}\right)\right]}{\partial q_{i}^{2}} \\
& =-\frac{p_{i}+s_{i}-p_{h}}{\alpha_{i}} f\left(\frac{q_{i}}{\alpha_{i}}\right) .
\end{aligned}
$$

For $f(\bullet)>0, \alpha_{i}>0$, and $p_{i}+s_{i}-p_{h}>0$, the secondorder condition of the expected profit function is strictly less than zero; that is, (2) is a strict concave function w.r.t. $q_{i}, i=$ $1,2, \cdots, n$. This completes the proof.

The total order quantity cannot be increased arbitrarily because of the restriction in retailer's own budget or storage space. Therefore, it is more practical for the retailer to consider the order quantity constraint in the ordering decision.

Furthermore, the constrained order quantity problem under MRPS is analyzed for the retailer. The total order quantity satisfies $\sum_{i=1}^{n} q_{i} \leq \bar{Q}_{0}$, where $\bar{Q}_{0}$ is the maximum of retailer's total order quantity. That is, the retailer's total order quantity must be less than or equal to $\bar{Q}_{0}$. Then the ordering model for maximizing expected profit is rewritten as

$$
\begin{aligned}
\max _{q_{i}} \quad E[\pi(\boldsymbol{q}, \xi)]=\sum_{i=1}^{n} E\left[\pi_{i}\left(q_{i}\right)\right] \\
\quad=\sum_{i=1}^{n}\left[\left(p_{i}\right.\right. \\
\left.+s_{i}\right) \int_{q_{i} / \alpha_{i}}^{\infty} q_{i} f(\xi) d \xi-s_{i} \int_{q_{i} / \alpha_{i}}^{\infty} \alpha_{i} \xi f(\xi) d \xi+\left(p_{i}\right. \\
\left.\left.\quad-p_{h}\right) \int_{0}^{q_{i} / \alpha_{i}} \alpha_{i} \xi f(\xi) d \xi+p_{h} \int_{0}^{q_{i} / \alpha_{i}} q_{i} f(\xi) d \xi-c q_{i}\right], \\
\text { s.t. } \quad \sum_{i=1}^{n} q_{i} \leq \bar{Q}_{0} .
\end{aligned}
$$

According to Lemma 1, the objective function of Model (6) is strictly concave w.r.t. $q_{i}$. In order to apply the Lagrangian multiplier method, Model (6) may be rewritten as the following one with equality constraint.

$$
\begin{array}{ll}
\max _{q_{i}} & E[\pi(\boldsymbol{q}, \xi)]=\sum_{i=1}^{n} E\left[\pi_{i}\left(q_{i}\right)\right], \\
\text { s.t. } & \sum_{i=1}^{n} q_{i}=Q_{0} .
\end{array}
$$

The Lagrangian multiplier function corresponding to Model (7) is

$$
\begin{aligned}
& L(\boldsymbol{q}, \lambda)=\sum_{i=1}^{n}\left[\left(p_{i}+s_{i}\right) \int_{q_{i} / \alpha_{i}}^{\infty} q_{i} f(\xi) d \xi\right. \\
& \quad-s_{i} \int_{q_{i} / \alpha_{i}}^{\infty} \alpha_{i} \xi f(\xi) d \xi+\left(p_{i}-p_{h}\right) \int_{0}^{q_{i} / \alpha_{i}} \alpha_{i} \xi f(\xi) d \xi \\
& \left.\quad+p_{h} \int_{0}^{q_{i} / \alpha_{i}} q_{i} f(\xi) d \xi-c q_{i}\right]+\lambda\left(\sum_{i=1}^{n} q_{i}-Q_{0}\right),
\end{aligned}
$$

where $\lambda$ is the Lagrangian multiplier.
Let the superscript $*$ denote optimality. Take the partial derivative of $L(\boldsymbol{q}, \lambda)$ w.r.t. $q_{i}$, and set the derivative to zero and solve $q_{i}$; then we obtain the optimal order quantity $q_{i}^{*}$ corresponding to $p_{i}$ :

$$
q_{i}^{*}=\alpha_{i} F^{-1}\left(\frac{p_{i}+s_{i}-c+\lambda^{*}}{p_{i}+s_{i}-p_{h}}\right), \quad i=1,2, \ldots, n .
$$

Note that the retailer's order quantity relates to the value of Lagrangian multiplier $\lambda$. When $\lambda$ in (9) is $\lambda^{*}$-the optimal Lagrangian multiplier-the optimal ordering strategy that maximizes the retailer's expected profit under order quantity constraint is obtained. The conclusions are as follows.

Theorem 2. In the case of order quantity constraint, the retailer's total optimal order quantity as per (9) satisfies the following condition:

$$
Q^{*}\left(\lambda^{*}\right)=\sum_{i=1}^{n} q_{i}^{*}=\sum_{i=1}^{n} \alpha_{i} F^{-1}\left(\frac{p_{i}+s_{i}-c+\lambda^{*}}{p_{i}+s_{i}-p_{h}}\right),
$$

where $\lambda^{*}$ satisfies $c-p_{i}-s_{i} \leq \lambda^{*}<c-p_{h}, i=1,2, \ldots, n$. 
Proof. Take the partial derivative of (8) w.r.t. $q_{i}$; then

$$
\begin{aligned}
\frac{\partial L(\boldsymbol{q}, \lambda)}{\partial q_{i}}= & -\left(p_{i}+s_{i}-p_{h}\right) \int_{0}^{q_{i} / \alpha_{i}} f(\xi) d \xi+p_{i}+s_{i} \\
& -c+\lambda \\
= & -\left(p_{i}+s_{i}-p_{h}\right) F\left(\frac{q_{i}}{\alpha_{i}}\right)+p_{i}+s_{i}-c+\lambda, \\
& i=1,2, \cdots, n .
\end{aligned}
$$

According to Lemma 1, the objective function of Model (6) is strictly concave w.r.t. $q_{i}$. Set the first-order condition of the Lagrangian multiplier function (8) to zero and solve $q_{i}$; then we get $q_{i}^{*}$ corresponding to $p_{i}$ :

$$
q_{i}^{*}=\alpha_{i} F^{-1}\left(\frac{p_{i}+s_{i}-c+\lambda^{*}}{p_{i}+s_{i}-p_{h}}\right), \quad i=1,2, \ldots, n .
$$

Therefore, the optimal ordering strategy under order quantity constraint is

$$
Q^{*}(\lambda)=\sum_{i=1}^{n} q_{i}^{*}=\sum_{i=1}^{n} \alpha_{i} F^{-1}\left(\frac{p_{i}+s_{i}-c+\lambda^{*}}{p_{i}+s_{i}-p_{h}}\right) .
$$

For $0 \leq F(\cdot) \leq 1$, we have $0 \leq\left(p_{i}+s_{i}-c+\lambda^{*}\right) /\left(p_{i}+s_{i}-\right.$ $\left.p_{h}\right) \leq 1$. However, when $\left(p_{i}+s_{i}-c+\lambda^{*}\right) /\left(p_{i}+s_{i}-p_{h}\right)=1$, $q_{i}^{*} \longrightarrow+\infty$, and $Q^{*}(\lambda) \longrightarrow+\infty$, the order quantity tends to be infinite, which is not in line with the actual situation. Therefore, $0 \leq\left(p_{i}+s_{i}-c+\lambda^{*}\right) /\left(p_{i}+s_{i}-p_{h}\right)<1$; that is, $c-p_{i}-s_{i} \leq \lambda^{*}<c-p_{h}$. This completes the proof.

Note. In Theorem 2 , the total order quantity $Q_{0}$ is a parameter, and we take $Q_{0}:=Q^{*}\left(\lambda^{*}\right)=\sum_{i=1}^{n} q_{i}^{*}$. The total order quantity is calculated according to (10) to ensure that the retailer maximizes his/her expected profit. Therefore, $Q^{*}\left(\lambda^{*}\right)$ in (10) is called the optimal total order quantity. If $\bar{Q}_{0}>\sum_{i=1}^{n} q_{i}^{*}$, the retailer's total order quantity is calculated according to (10), and $q_{i}^{*}$ in (9) is the optimal order quantity for Model (6); if $\bar{Q}_{0}<\sum_{i=1}^{n} q_{i}^{*}$, the retailer's total order quantity is calculated based on a given order quantity $\bar{Q}_{0}$, but it is not the optimal total order quantity and $q_{i}^{*}$ in (9) is not the optimal order quantity for Model (6).

Theorem 3. If $\lambda^{*}=0$, then Model (6) degenerates into an unconstrained problem, so the optimal total order quantity is

$$
Q_{N}^{*}=\sum_{i=1}^{n} q_{i}^{*}=\sum_{i=1}^{n} \alpha_{i} F^{-1}\left(\frac{p_{i}+s_{i}-c}{p_{i}+s_{i}-p_{h}}\right) .
$$

Proof. Eq. (2) is strictly concave w.r.t. $q_{i}$. Hence, set (4) to zero; then we have

$$
F\left(\frac{q_{i}^{*}}{\alpha_{i}}\right)=\frac{p_{i}+s_{i}-c}{p_{i}+s_{i}-p_{h}} .
$$

Therefore, when there is no order quantity constraint, the optimal ordering strategy to maximize the retailer's expected profit is

$$
Q_{N}^{*}=\sum_{i=1}^{n} q_{i}^{*}=\sum_{i=1}^{n} \alpha_{i} F_{i}^{-1}\left(\frac{p_{i}+s_{i}-c}{p_{i}+s_{i}-p_{h}}\right) .
$$

Substitute $\lambda=0$ into (10); the optimal ordering strategy with order quantity constraint is the same as the above. This completes the proof.

When $n=1, Q_{N}^{*}$ in (14) is the optimal total order quantity when the retailer adopts SRPS, which is the same as the conclusion of the classic newsboy model.

When the relevant parameters change, the optimal ordering strategy will change accordingly. And the following conclusions are obvious.

Corollary 4. When $p_{i}, s_{i}$, and $p_{h}$ are fixed, $q_{i}^{*}$ decreases with the increase in $c$, and so does $\sum_{i=1}^{n} q_{i}^{*}$.

Proof. From (9), we have the following.

$$
\left(p_{i}+s_{i}-p_{h}\right) F\left(\frac{q_{i}^{*}}{\alpha_{i}}\right)=p_{i}+s_{i}-c+\lambda^{*}
$$

The first derivative of (17), w.r.t. $c$, is

$$
\left(p_{i}+s_{i}-p_{h}\right) F^{\prime}\left(\frac{q_{i}^{*}}{\alpha_{i}}\right) \frac{1}{\alpha_{i}} \frac{\partial q_{i}^{*}}{\partial c}=-1 .
$$

For $p_{i}+s_{i}-p_{h}>0, \alpha_{i}>0, F^{\prime}\left(q_{i}^{*} / \alpha_{i}\right)>0$, we get $\partial q_{i}^{*} / \partial c<$ 0 , so $\left(\partial \sum_{i=1}^{n} q_{i}^{*}\right) / \partial c=\partial q_{i}^{*} / \partial c<0$, which implies $\partial q_{i}^{*} / \partial c$ and $\left(\partial \sum_{i=1}^{n} q_{i}^{*}\right) / \partial c$ are negative. This proves that $q_{i}^{*}$ and $\sum_{i=1}^{n} q_{i}^{*}$ decrease with the increase in $c$. This completes the proof.

Corollary 5. When $p_{i}, c$, and $p_{h}$ are fixed, $q_{i}^{*}$ increases with the increase in $s_{i}$, and so does $\sum_{i=1}^{n} q_{i}^{*}$.

Proof. The first derivative of (17), w.r.t. $s_{i}$, is

$$
F\left(\frac{q_{i}^{*}}{\alpha_{i}}\right)+\left(p_{i}+s_{i}-p_{h}\right) F^{\prime}\left(\frac{q_{i}^{*}}{\alpha_{i}}\right) \frac{1}{\alpha_{i}} \frac{\partial q_{i}^{*}}{\partial s_{i}}=1,
$$

that is

$$
\left(p_{i}+s_{i}-p_{h}\right) F^{\prime}\left(\frac{q_{i}^{*}}{\alpha_{i}}\right) \frac{1}{\alpha_{i}} \frac{\partial q_{i}^{*}}{\partial s_{i}}=1-F\left(\frac{q_{i}^{*}}{\alpha_{i}}\right) .
$$

In (20), the right side is $1-F\left(q_{i}^{*} / \alpha_{i}\right)>0$, the left $p_{i}+$ $s_{i}-p_{h}>0, \alpha_{i}>0$, and $F^{\prime}\left(q_{i}^{*} / \alpha_{i}\right)>0$, so we get $\partial q_{i}^{*} / \partial s_{i}>0$, and then $\left(\partial \sum_{i=1}^{n} q_{i}^{*}\right) / \partial s_{i}=\partial q_{i}^{*} / \partial s_{i}>0$, which proves that $q_{i}^{*}$ and $\sum_{i=1}^{n} q_{i}^{*}$ increase with the increase in $s_{i}$. This completes the proof.

Corollary 6. When $p_{i}, c$, and $s_{i}$ are fixed, $q_{i}^{*}$ increases with the increase in $p_{h}$, and so does $\sum_{i=1}^{n} q_{i}^{*}$.

Proof. The first derivative of (17), w.r.t. $p_{h}$, is

$$
-F\left(\frac{q_{i}^{*}}{\alpha_{i}}\right)+\left(p_{i}+s_{i}-p_{h}\right) F^{\prime}\left(\frac{q_{i}^{*}}{\alpha_{i}}\right) \frac{1}{\alpha_{i}} \frac{\partial q_{i}^{*}}{\partial p_{h}}=0,
$$

that is

$$
\left(p_{i}+s_{i}-p_{h}\right) F^{\prime}\left(\frac{q_{i}^{*}}{\alpha_{i}}\right) \frac{1}{\alpha_{i}} \frac{\partial q_{i}^{*}}{\partial s_{i}}=F\left(\frac{q_{i}^{*}}{\alpha_{i}}\right) .
$$


In (22), the right side $F\left(q_{i}^{*} / \alpha_{i}\right)>0$, the left $p_{i}+s_{i}-p_{h}>$ $0, \alpha_{i}>0$, and $F^{\prime}\left(q_{i}^{*} / \alpha_{i}\right)>0$, so we get $\partial q_{i}^{*} / \partial p_{h}>0$ and $\left(\partial \sum_{i=1}^{n} q_{i}^{*}\right) / \partial p_{h}=\partial q_{i}^{*} / \partial p_{h}>0$, which proves that $q_{i}^{*}$ and $\sum_{i=1}^{n} q_{i}^{*}$ increase with the increase in $p_{h}$. This completes the proof.

Corollary 7. When $c, s_{i}$, and $p_{h}$ are fixed, $q_{i}^{*}$ increases with the increase in $p_{i}$, and so does $\sum_{i=1}^{n} q_{i}^{*}$.

Proof. The first derivative of (17), w.r.t. $p_{i}$, is

$$
F\left(\frac{q_{i}^{*}}{\alpha_{i}}\right)+\left(p_{i}+s_{i}-p_{h}\right) F^{\prime}\left(\frac{q_{i}^{*}}{\alpha_{i}}\right) \frac{1}{\alpha_{i}} \frac{\partial q_{i}^{*}}{\partial p_{i}}=1,
$$

that is

$$
\left(p_{i}+s_{i}-p_{h}\right) F^{\prime}\left(\frac{q_{i}^{*}}{\alpha_{i}}\right) \frac{1}{\alpha_{i}} \frac{\partial q_{i}^{*}}{\partial p_{i}}=1-F\left(\frac{q_{i}^{*}}{\alpha_{i}}\right) .
$$

In (24), the right side $1-F\left(q_{i}^{*} / \alpha_{i}\right)>0$, the left $p_{i}+s_{i}-$ $p_{h}>0, \alpha_{i}>0$, and $F^{\prime}\left(q_{i}^{*} / \alpha_{i}\right)>0$, so we get $\partial q_{i}^{*} / \partial p_{i}>0$ and $\left(\partial \sum_{i=1}^{n} q_{i}^{*}\right) / \partial p_{i}=\partial q_{i}^{*} / \partial p_{i}>0$, which proves that $q_{i}^{*}$ and $\sum_{i=1}^{n} q_{i}^{*}$ increase with the increase in $p_{i}$. This completes the proof.

Corollary 8. When $p_{1}, c, s_{i}$, and $p_{h}$ are fixed, we have two cases: when $n>1$ and $i>1, q_{i}^{*}$ decreases with the increase in $d$; when $i=1, q_{i}^{*}$ is unrelated to $d$. Therefore, when $n>1$ (i.e., MRPS is adopted), $\sum_{i=1}^{n} q_{i}^{*}$ decreases with the increase in d; when $n=1$ (i.e., SRPS is adopted), $q_{1}^{*}$ is the optimal total order quantity, and it is unrelated to $d$.

Proof. With $p_{i}=(1-(i-1) d) p_{1}$ and (17), we get

$$
\begin{gathered}
{\left[(1-(i-1) d) p_{1}+s_{i}-p_{h}\right] F\left(\frac{q_{i}^{*}}{\alpha_{i}}\right)} \\
\quad=(1-(i-1) d) p_{1}+s_{i}-c+\lambda^{*} .
\end{gathered}
$$

The first derivative of (25) w.r.t. $d$ is

$$
\begin{aligned}
- & (i-1) p_{1} F\left(\frac{q_{i}^{*}}{\alpha_{i}}\right) \\
& +\left[(1-(i-1) d) p_{1}+s_{i}-p_{h}\right] F^{\prime}\left(\frac{q_{i}^{*}}{\alpha_{i}}\right) \frac{1}{\alpha_{i}} \frac{\partial q_{i}^{*}}{\partial d} \\
= & -(i-1) p_{1},
\end{aligned}
$$

that is

$$
\begin{aligned}
& {\left[(1-(i-1) d) p_{1}+s_{i}-p_{h}\right] F^{\prime}\left(\frac{q_{i}^{*}}{\alpha_{i}}\right) \frac{1}{\alpha_{i}} \frac{\partial q_{i}^{*}}{\partial d}} \\
& \quad=-(i-1) p_{1}\left[1-F\left(\frac{q_{i}^{*}}{\alpha_{i}}\right)\right] .
\end{aligned}
$$

When $n>1$ and $i>1$, the right side of $(27)-(i-1) p_{1}[1-$ $\left.F\left(q_{i}^{*} / \alpha_{i}\right)\right]<0$, and the left side $(1-(i-1) d) p_{1}+s_{i}-p_{h}=$ $p_{i}+s_{i}-p_{h}>0, \alpha_{i}>0, F^{\prime}\left(q_{i}^{*} / \alpha_{i}\right)>0$, so we get $\partial q_{i}^{*} / \partial d<0$, which proves that $q_{i}^{*}$ decreases with the increase in $d$ when $n>1$ and $i>1$.

When $i=1,(9)$ becomes $q_{1}^{*}=\alpha_{1} F^{-1}\left(\left(p_{1}+s_{1}-c+\lambda^{*}\right) /\left(p_{1}+\right.\right.$ $\left.\left.s_{1}-p_{h}\right)\right)$, where $d$ is not found, so $q_{1}^{*}$ is unrelated to $d$.

When $n>1,\left(\partial \sum_{i=1}^{n} q_{i}^{*}\right) / \partial d=\partial q_{i}^{*} / \partial d<0$; when $n=1, q_{1}^{*}$ is the optimal total order quantity, and it is unrelated to $d$. This completes the proof.

\section{MRPS Algorithm}

To solve the retailer MRPS ordering problem with order quantity constraint, $\lambda^{*}$ should be first found. The MRPS algorithm is proposed to find the approximate optimal value of Lagrangian multiplier $\tilde{\lambda}^{*}$ after which the approximate optimal total order quantity $\widetilde{Q}^{*}$ is solved.

The step-by-step procedure of MRPS algorithm is given as follows.

Initialization. Set the initial value of the parameters (see Section 5.1).

Step 1. Determine the interval range of Lagrangian multiplier $\lambda$. Set $\lambda_{\text {min }}=\max _{i}\left\{c-p_{i}-s_{i}\right\}$ and $\lambda_{\text {max }}=c-p_{h}$; then $\lambda_{\text {min }} \leq \lambda<\lambda_{\text {max }}$.

Step 2. Take $M$ values in the interval range of $\lambda$ uniformly. Set $\Delta \lambda=\left(\lambda_{\text {max }}-\lambda_{\text {min }}\right) /(M+1)$; the range of $\lambda$ is divided into $M+1$ intervals with the length of $\Delta \lambda$, and the value of $\lambda^{(k)}$ is $\lambda_{\text {min }}+k \Delta \lambda, k=1,2, \ldots, M$.

Step 3. Substitute $\lambda^{(k)}$ into (8) to calculate $q_{i}^{(k)}$, where $i=$ $1,2, \ldots, n, k=1,2, \ldots, M$; then calculate $\sum_{i=1}^{n} q_{i}^{(k)}$, where $k=1,2, \ldots, M$.

Step 4. Determine the approximate optimal value of Lagrangian multiplier $\widetilde{\lambda}^{*}$. Find $\sum_{i=1}^{n} q_{i}^{\left(k^{*}\right)}$ which is closest to $\bar{Q}_{0}$; that is, $\left|\bar{Q}_{0}-\sum_{i=1}^{n} q_{i}^{\left(k^{*}\right)}\right|=\min _{k}\left|\bar{Q}_{0}-\sum_{i=1}^{n} q_{i}^{(k)}\right|$, where $k=1,2, \ldots, M$; then $\widetilde{\lambda}^{*}=\lambda^{\left(k^{*}\right)}$

Step 5. Calculate the approximate optimal total order quantity $\widetilde{Q}^{*}$ and the corresponding expected profit $\widetilde{E}^{*}$ for the retailer under the order quantity constraint. Comparing $\sum_{i=1}^{n} q_{i}^{\left(k^{*}\right)}$ with $\bar{Q}_{0}$, we have two cases.

Case 1. When $\sum_{i=1}^{n} q_{i}^{\left(k^{*}\right)} \leq \bar{Q}_{0}$, the approximate optimal total order quantity $\widetilde{Q}^{*}$ is $\sum_{i=1}^{n} q_{i}^{\left(k^{*}\right)}$; then substitute $q_{i}^{\left(k^{*}\right)}$ into (4) to calculate the retailer's expected profit $\widetilde{E}^{*}=\sum_{i=1}^{n} \mathrm{E}\left[\pi_{i}\left(q_{i}^{\left(k^{*}\right)}\right)\right]$.

Case 2. When $\sum_{i=1}^{n} q_{i}^{\left(k^{*}\right)}>\bar{Q}_{0}, \bar{Q}_{0}$ should be taken as the total order quantity, and as $\bar{Q}_{0}$ usually satisfies $\sum_{i=1}^{n-j} q_{i}^{\left(k^{*}\right)}<$ $\bar{Q}_{0}<\sum_{i=1}^{n-j+1} q_{i}^{\left(k^{*}\right)}$, where $j=1,2, \ldots, n$, then the retailer's expected profit is $\widetilde{E}^{*}=\sum_{i=1}^{n-j} \mathrm{E}\left[\pi_{i}\left(q_{i}^{\left(k^{*}\right)}\right)\right]+\mathrm{E}\left[\pi_{n-j+1}\left(q_{n-j+1}^{\left(k^{*}\right)}-\right.\right.$ $\left.\left.\left(\sum_{i=1}^{n-j+1} q_{i}^{\left(k^{*}\right)}-\bar{Q}_{0}\right)\right)\right]$.

Examples are given in the next section to calculate the optimal ordering strategy of retailers who adopt SRPS and 
MRPS, respectively, and to verify the validity of the extended newsboy model.

\section{Numerical Example}

Take a real case of fruit stores as an example to illustrate the optimal ordering strategy and expected profit for retailers who sell the same product at one or multiple retail prices simultaneously. The results with and without order quantity constraint, applying SRPS or MRPS, are shown, respectively. The effect of price discount coefficient and demand volatility on retailer's MRPS is analyzed through sensitivity analysis.

5.1. Case Description. Three fruit stores, A, B, and C, in Xihu District, Hangzhou, are surveyed. They are similar in scale and all locate near the open agriculture market with similar population density but in different communities. The three retailers adopt different pricing strategies to sell Quzhou ponkan (a kind of orange commonly available in December, also known as Chinese honey orange) of the same quality in a package of 5kg per box: Retailer A adopts a SRPS of CNY 35 per box, Retailers B and C adopt MRPS, of which Retailer B uses the prices strategy of CNY 35 per box and CNY 68 every 2 boxes, and Retailer $C$ uses the prices strategy of CNY 35 per box, CNY 68 every 2 boxes, and CNY 99 every 3 boxes. Then we have $p^{(1)}=35, p^{(2)}=(35,34)$, and $p^{(3)}=(35,34,33)$ to denote the pricing strategies of Retailers $A, B$, and $C$, respectively, and the price discount coefficient $d=1 / 35$.

The daily sales data from December 17, 2017, to February 14, 2018, and from February 25, 2018, to March 31, 2018, is collected. The missing days in February are in the Spring Festival, the holiday, when stores are closed. The sales season of Quzhou ponkan usually starts from every December and finishes in April the next year. Due to the different beginning and ending time of the three retailers here, our data only cover the above period. Figure 1(a) shows daily sales volume of Retailers A, B, and C and Figure 1(b) C's daily sales volume at each price.

Every 5 days, the three retailers place the order. It is found that the sales volume for every ordering period approximately obeys normal distribution with $\mu^{(1)}=406.42, \sigma^{(1)}=63.40$; $\mu^{(2)}=671.95, \sigma^{(2)}=81.24$; and $\mu^{(3)}=768.74, \sigma^{(3)}=106.97$. As per the definition of the demand ratio $\alpha$ in Section 3, it is easy to get $\alpha^{(1)}=1, \alpha^{(2)}=(0.29,0.71)$, and $\alpha^{(3)}=(0.14,0.33,0.53)$. And $c^{(i)}=15, p_{h}^{(i)}=5$, and $s^{(i)}=p^{(i)}-c^{(i)}$ are the order cost, the disposed price, and shortage cost per box, respectively, and $\bar{Q}_{0}^{(i)}=700$, where $i=1,2,3$, is the total order quantity for any of the three retailers.

5.2. Optimal Ordering Strategy. $M=100$ is taken. The initial values of all the parameters are shown in Section 5.1. The MRPS algorithm in Section 4 is used to calculate the optimal total order quantity and the expected profit of Retailers A, B, and $\mathrm{C}$. The corresponding results are illustrated in Figures 2 and 3 , respectively.

When there is order quantity constraint, the approximate optimal Lagrangian multiplier $\tilde{\lambda}^{*}$, the abscissa value corresponding to the order quantity closest to $\bar{Q}_{0}$, is shown in Figure 2, after which the retailer's approximate optimal total order quantity and expected profit are calculated and shown using the MRPS algorithm. According to Theorem 3, when $\lambda^{*}=0$, the constrained problem degenerates into an unconstrained problem and the expected profit is maximum as shown in Figure 3 with the optimal total order quantity in Figure 2. Table 3 shows the comparison between the results with and without order quantity constraint, namely, the specific values marked in Figures 2 and 3.

With MRPS, the order quantity and expected profit increase considerably, which explains why retailers use MRPS as frequently used discount strategy and verifies the effectiveness of the extended newsboy model.

Observing the left and right ends of the total order quantity curves in Figure 2 and the expected profit curves in Figure 3, it is found that the retailer should not increase or reduce the order quantity blindly. MRPS $(n>1)$ is better than SRPS $(n=1)$. The incremental revenue brought by MRPS to retailers gradually decreases with the increase in $n$ in the case without order quantity constraint; i.e., the expected profit when $n=2$ is $63 \%$ higher than the expected profit when $n=1$, while the expected profit when $n=3$ is only $8 \%$ higher than the expected profit when $n=2$ as shown in Figure 3 and Table 3. Therefore the retailer cannot blindly increase $n$ to increase revenue in the case with order quantity constraint. In Figure 2, when $n=2,3$, the optimal ordering strategies are the same, both of which are $\bar{Q}_{0}$; however the expected profit is the largest when $n=2$ as shown in Figure 3 and Table 3. Hence, the retailer who sells the product at $n$ different quantitydiscount prices simultaneously in the case with order quantity constraint should control $n$. In other words, a larger $n$ does not mean a better expected profit for the retailer. Therefore, order quantity constraint has an effect on the retailer's choice of MRPS.

Note. In Figures 2 and 3 , $\star$ represents the approximate optimal total order quantity and expected profit corresponding to $\widetilde{\lambda}^{*}$ with order quantity constraint; represents the optimal total order quantity and expected profit without order quantity constraint.

From Table 3, it is found that the expected profit without order quantity constraint is more than that with order quantity constraint, which is easy to understand: when $n=1$ (i.e., Retailer A adopts SRPS), the risk of excessive orders increases, while the loss due to shortage is reduced which is not sufficient to compensate for the losses caused by excessive orders, thus resulting in a decrease in the expected profit; when $n>1$ (i.e., Retailers $B$ and $C$ adopt MRPS), the risk of shortage increases, while the loss due to excessive order is reduced, a reduction which is not enough to make up for the increase in shortage loss, thus resulting in a decrease in the expected profit.

The difference in retailer's optimal ordering strategy between with and without order quantity constraint is further explained by Lagrangian multiplier. The Lagrangian multiplier can reflect the effect of changes in order quantity constraint on the retailer's optimal total order quantity; therefore, 


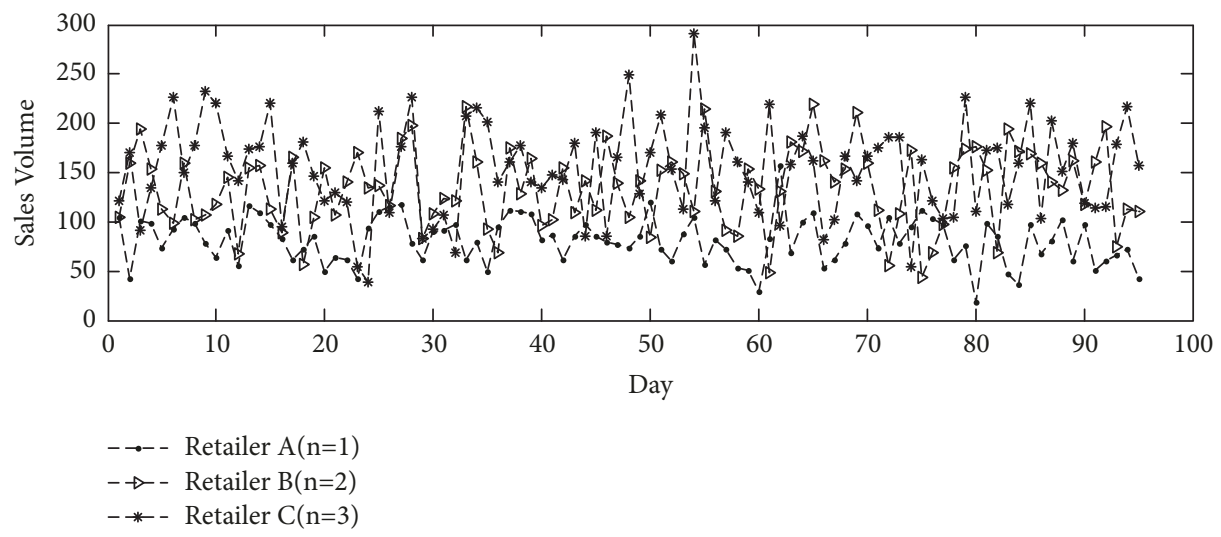

(a) Daily sales volume

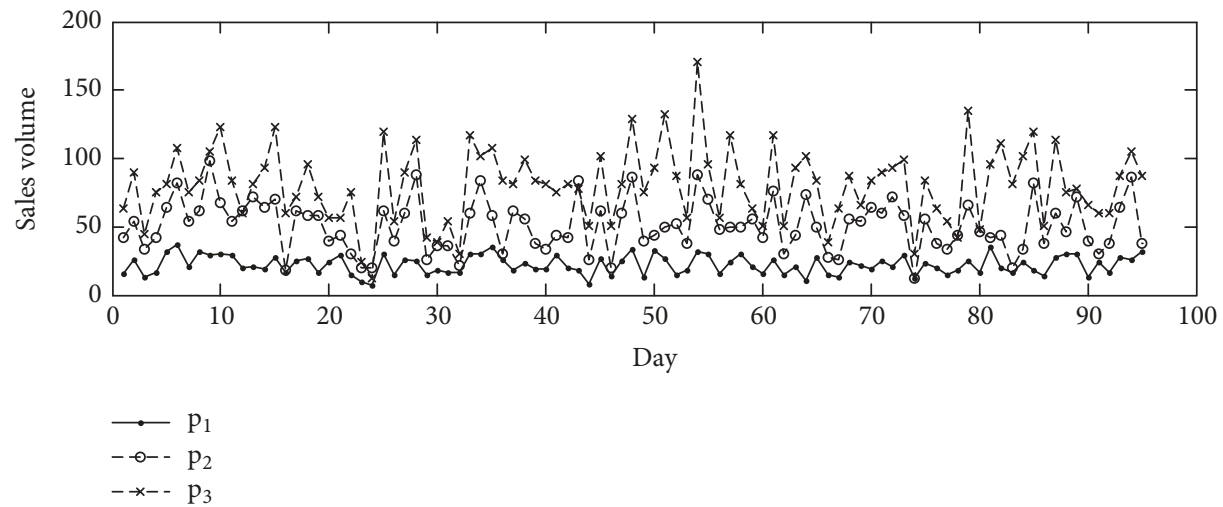

(b) Daily sales volumes at each price

Figure 1

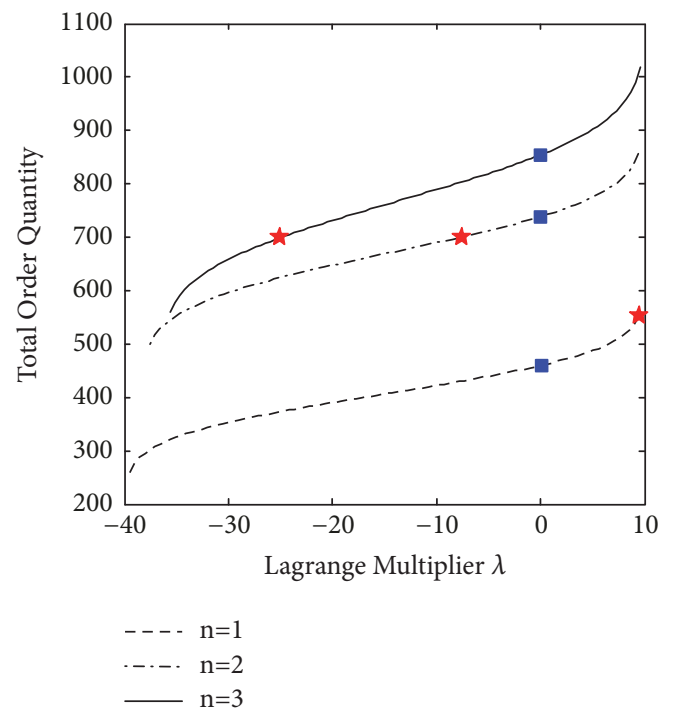

FIGURE 2: Retailer's total order quantity.

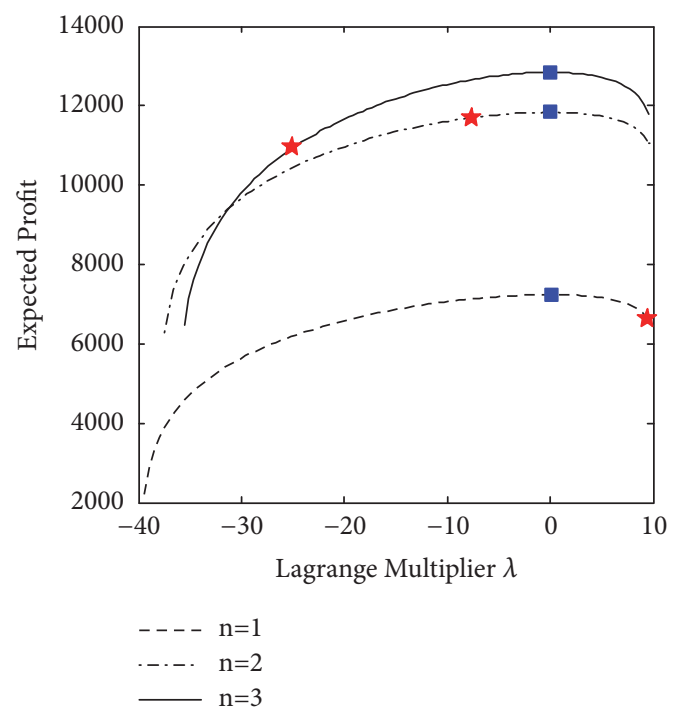

FIGURE 3: Retailer's expected profit. change in $\lambda^{*}$ can reflect the change in the retailer's optimal ordering strategy in the case with order quantity constraint. As illustrated in Figure 2, when $n=1$, the approximate optimal value of Lagrangian multiplier $\widetilde{\lambda}^{*}$ is at the right end of the total order quantity curve, and the approximate optimal total order quantity is much larger than that without the order quantity constraint; when $n=2, \tilde{\lambda}^{*}$ is on the left side of the zero, and the approximate optimal total order quantity is 
smaller than that without order quantity constraint; when $n=3, \tilde{\lambda}^{*}$ is close to the left end of the total order quantity curve, and the approximate optimal total order quantity is much smaller than the case without the order quantity constraint. Therefore, the order quantity constraint has a significant effect on the retailer's optimal ordering strategy.

5.3. Sensitivity Analysis. The unit sales price $p_{i}$ is greater than the unit ordering cost $c$, so we get $0<\left(p_{i}-c\right) / p_{i}<1$. According to the proof of Theorem 2 , we have $0 \leq\left(p_{i}+s_{i}-\right.$ $c+\lambda) /\left(p_{i}+s_{i}-p_{h}\right)<1$.

The purpose of the retailer adopting MRPS is to increase sales and gain more profit, when $i<j$ and $p_{i}>p_{j}$, but the retailer's profit selling $j$ unit products at the favorable price $p_{j}$ is less than that selling $i$ unit products at $p_{i}$; i.e., $i\left(p_{i}-c\right) \leq j\left(p_{j}-c\right)$; otherwise, the retailer will not sell products at the low price $p_{j}$. However, consumers want to spend less and buy more. When $i<j$ and $p_{i}>p_{j}$, then the consumer purchasing $j$ units at a favorable price $p_{j}$ spends more than that purchasing $i$ units at a price $p_{i}$; i.e., $i p_{i} \leq j p_{j}$; otherwise the demand at unit price $p_{i}$ is zero, and the retailer will not gain any sales at the high price $p_{i}$.

In selling seasons, retailers using MRPS have to determine reasonable quantity discounts for the product, i.e., determine price discount factor $d$, in order to increase sales and profits. Meanwhile, retailers' sales as well as profits are affected by demand uncertainty (i.e., demand volatility). On the basis of the above, we analyze the effect of price discount coefficient and demand volatility on the retailer's MRPS, respectively.

\subsubsection{Effect of Price Discount Coefficient on the Retailer's} MRPS. The sensitivity analysis is performed for $d$ varying from 0.01 to 0.14 , as any $d$ otherwise does not conform to the reality described above. In this part of the study, it is assumed the other parameters remain unchanged. Regardless of the order quantity constraint, the expected profit of the retailer corresponding to different discount coefficients is calculated, as shown in Figures 4(a) and 4(b).

As illustrated in Figures 4(a) and 4(b), when $n=1$, the price discount coefficient does not affect the expected profit. When $n>1$, the price discount coefficient affects the expected profit; as shown from each profit curve, the expected profit decreases gradually with the increase in $d$.

When the retailer offers consumers more favorable prices, the results without the order quantity constraint are different from that with order quantity constraint. Figure 4(a) shows the increases in retailer's expected profit with the increase in $n$ in the case without order quantity constraint. With the increase in $n$, the expected profit of the retailer who adopts MRPS increases significantly when the discount coefficient is low. At the same time, the decrease in expected profit is more obvious when the effect of discount coefficient on expected profit increases with the increase in $n$, especially when $n=3$. The expected profit curve when $n=3$ is below that when $n=2$ when the discount coefficient is high. Figure 4(b) shows that in the case with order quantity constraint, when $n \leq 2$, the retailer's expected profit increases with the increase in $n$, and when $n=3$, the expected profit curve is always below the one when $n=2$.

The results show that no matter whether the order quantity constraint exists, MRPS is superior to the SRPS. But the effect of the price discount coefficient on the retailer's choice of MRPS is different depending on whether there is an order quantity constraint. When there exists no order quantity constraint, the retailer needs to determine $n$ according to the size of discount coefficient. In the condition with order quantity constraint, the retailer should control $n$ when adopting MRPS.

5.3.2. Effect of Demand Volatility on the Retailer's MRPS. The standard deviation is always used to show the volatility of demand. To better understand the effect of demand volatility on the retailer's MRPS, the standard deviation is set at 0.5 to 2.5 times of the initial standard deviation $\sigma^{(i)}$ in Section 5.1, represented by $\sigma_{m}^{(i)}$, where $i=1,2,3, m=1,2, \cdots, 5$. In this part of the study, it is assumed that the other parameters remain unchanged. Then the optimal total order quantity and the expected profit of the retailer corresponding to different demand volatility under the condition with and without order quantity constraint are calculated, with the corresponding results shown in Tables 4(a), 4(b), 5(a), and 5(b).

The results illustrated in Tables $4(\mathrm{a})$ and 4(b) show, respectively, that with the increase in demand volatility the optimal total order quantity increases gradually when there exists no order quantity constraint, and the approximate optimal total order quantity increases gradually until the total order quantity $\bar{Q}_{0}$ is reached under the condition of order quantity constraint. The results illustrated in Tables 5(a) and 5(b) show that the expected profit decreases with the increase of demand volatility in both cases. Due to demand uncertainty, the retailer might choose to increase order quantity to cope with the possibility of an increase in demand, and then the loss arising from excessive orders may increase. However, shortage loss may increase if the retailer's optimal total order quantity reaches the condition of order quantity constraint. As a result, the optimal total order quantity and the approximate optimal total order quantity increase but the expected profit decreases.

As shown in Tables 5(a) and 5(b), the expected profit without order quantity constraint is the largest when $n=3$ and the expected profit with order quantity constraint is the largest when $n=2$. Therefore, no matter whether an order quantity constraint exists, the demand volatility does not affect the retailer's choice of MRPS. The expected profit increases gradually with the increase in $n$. The retailer without order quantity constraint tends to choose MRPS with a larger $n$. Meanwhile, the retailer with order quantity constraint has to control $n$ when adopting MRPS.

\section{Conclusion}

With the above analysis, the following managerial inspirations are drawn:

(1) The retailer's optimal ordering strategy may not be realized when the order quantity is constrained. To obtain 


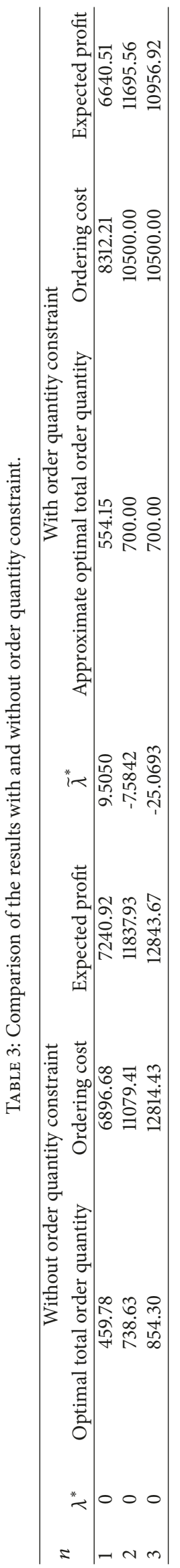




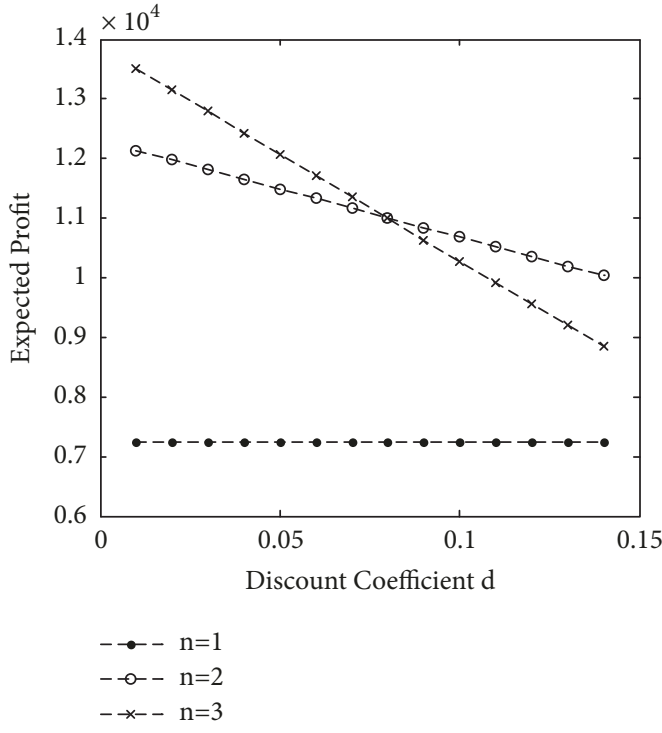

(a) Without order quantity constraint

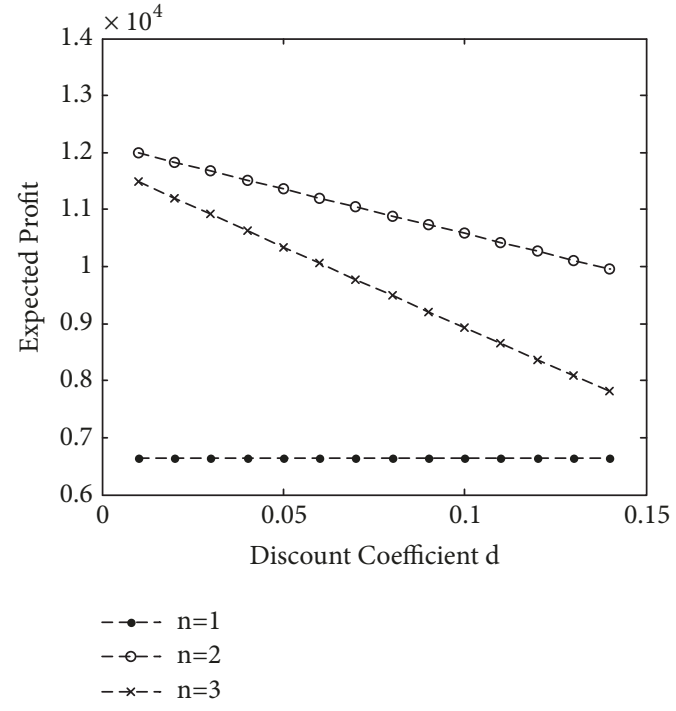

(b) With order quantity constraint

FIGURE 4: Effect of discount coefficient on the retailer's expected profit.

TABLE 4

(a) Optimal total order quantity without order quantity constraint when demand standard deviation increases

\begin{tabular}{cccccc}
\hline$n$ & $\begin{array}{c}\text { Optimal total order } \\
\text { quantity of } \sigma_{1}^{(i)}\end{array}$ & $\begin{array}{c}\text { Optimal total order } \\
\text { quantity of } \sigma_{2}^{(i)}\end{array}$ & $\begin{array}{c}\text { Optimal total order } \\
\text { quantity of } \sigma_{3}^{(i)}\end{array}$ & $\begin{array}{c}\text { Optimal total order } \\
\text { quantity of } \sigma_{4}^{(i)}\end{array}$ & $\begin{array}{c}\text { Optimal total order } \\
\text { quantity of } \sigma_{5}^{(i)}\end{array}$ \\
\hline 1 & 433.10 & 459.78 & 486.46 & 513.14 & 539.82 \\
2 & 705.29 & 738.63 & 771.97 & 805.30 & 838.64 \\
3 & 811.52 & 854.30 & 897.07 & 939.85 & 982.63 \\
\hline
\end{tabular}

(b) Approximate optimal total order quantity with order quantity constraint when demand standard deviation increases

\begin{tabular}{cccccc}
\hline & $\begin{array}{c}\text { Approximate optimal } \\
\text { total order quantity of } \\
\sigma_{1}^{(i)}\end{array}$ & $\begin{array}{c}\text { Approximate optimal } \\
\text { total order quantity of }\end{array}$ & $\begin{array}{c}\text { Approximate optimal } \\
\text { total order quantity of }\end{array}$ & $\begin{array}{c}\text { Approximate optimal } \\
\text { total order quantity of } \\
\sigma_{2}^{(i)}\end{array}$ & $\begin{array}{c}\text { Approximate optimal } \\
\text { total order quantity of } \\
\sigma_{5}^{(i)}\end{array}$ \\
\hline 1 & 480.28 & 554.15 & 628.01 & 700.00 & 700.00 \\
2 & 700.00 & 700.00 & 700.00 & 700.00 & 700.00 \\
3 & 700.00 & 700.00 & 700.00 & 700.00 & 700.00 \\
\hline
\end{tabular}

\section{TABLE 5}

(a) Expected profit without order quantity constraint when demand standard deviation increases

\begin{tabular}{cccccc}
\hline$n$ & Expected profit of $\sigma_{1}^{(i)}$ & Expected profit of $\sigma_{2}^{(i)}$ & Expected profit of $\sigma_{3}^{(i)}$ & Expected profit of $\sigma_{4}^{(i)}$ & Expected profit of $\sigma_{5}^{(i)}$ \\
\hline 1 & 7684.66 & 7240.92 & 6797.16 & 6352.40 & 5903.54 \\
2 & 12399.92 & 11837.93 & 11275.94 & 10713.89 & 10150.72 \\
3 & 13574.96 & 12843.67 & 12112.37 & 11380.56 & 10644.38 \\
\hline
\end{tabular}

(b) Expected profit with order quantity constraint when demand standard deviation increases

\begin{tabular}{cccccc}
\hline$n$ & Expected profit of $\sigma_{1}^{(i)}$ & Expected profit of $\sigma_{2}^{(i)}$ & Expected profit of $\sigma_{3}^{(i)}$ & Expected profit of $\sigma_{4}^{(i)}$ & Expected profit of $\sigma_{5}^{(i)}$ \\
\hline 1 & 7384.45 & 6640.51 & 5896.53 & 5168.73 & 5083.21 \\
2 & 12394.99 & 11695.56 & 10938.99 & 10167.57 & 9388.90 \\
3 & 11634.22 & 10956.92 & 10078.31 & 9137.94 & 8170.12 \\
\hline
\end{tabular}


higher expected profit, the retailer needs to relax the budget. When there exists no order quantity constraint, the retailer who adopts MRPS should choose a larger $n$. As order quantity constraint has an effect on the choice of the retailer's MRPS, the retailer should choose a larger $n$ but put it under control, when an order quantity constraint exists.

(2) As the expected profit decreases gradually with the increase in discount coefficient, when adopting MRPS, the retailer should try their best to prevent the discount coefficient from being too high and make prudent decisions on the discount coefficient to maintain a certain profit level. The price discount coefficient has an effect on retailer's choice of MRPS when there is no order quantity constraint; thus the retailer needs to consider discount coefficient and order quantity constraint when deciding on the number of retail prices.

(3) Because an inverse relationship exists between demand volatility and expected profit, the retailer should reduce the effect of demand volatility on the expected profit through various methods, such as demand forecasting. Furthermore, the demand volatility has no effect on retailer's choice of MRPS in the case without order quantity constraint; therefore the retailer does not need to consider demand volatility when deciding the number of retail prices.

The above inspirations can provide a reference for the realization of retailer's optimal ordering strategy and profit maximization. And further studies could cover the following areas: different categories of products, consumer purchasing tendency, transition probability, risk-averse retailer, etc.

\section{Data Availability}

The data used to support the findings of this study are available from the corresponding author upon request.

\section{Conflicts of Interest}

The authors declare that there are no conflicts of interest regarding the publication of this paper.

\section{Acknowledgments}

This work is supported by the Natural Science Foundation of Zhejiang Province, Grant No. LY18A010031, and the National Natural Science Foundation of China, Grants No. 11871434 and No. 11771386.

\section{References}

[1] F. Akaichi, R. M. Nayga, and J. M. Gil, "Effect of price-discount distribution in multi-unit price promotions on consumers' willingness to pay, sales value, and retailers' revenue," Agribusiness, vol. 31, no. 1, pp. 14-32, 2015.

[2] R. C. Blattberg and S. A. Neslin, Sales Promotion: Concepts, Methods and Strategies, Prentice Hall, Englewood Cliffs, NJ, USA, 1990.

[3] W. H. Huang, "How consumers respond to missing a quantity discount with multiple price breaks," Journal of Consumer Behaviour, vol. 15, no. 5, pp. 411-419, 2016.
[4] B. Wansink, R. J. Kent, and S. J. Hoch, "An anchoring and adjustment model of purchase quantity decisions," Journal of Marketing Research, vol. 35, no. 1, pp. 71-81, 1998.

[5] M. Iranmanesh, K. Jayaraman, B. C. Imrie, and S. Zailani, "Promoting products through volume discount: evidence from Malaysia," Journal of Promotion Management, vol. 22, no. 1, pp. 71-88, 2016.

[6] K. C. Manning and D. E. Sprott, "Multiple unit price promotions and their effects on quantity purchase intentions," Journal of Retailing, vol. 83, no. 4, pp. 411-421, 2007.

[7] M. Iranmanesh, K. Jayaraman, S. H. B. D. M. Zailani, and S. M. Ghadiri, "The effects of consumer perception of volume discount benefits on intention to purchase grocery products," Asia Pacific Journal of Marketing and Logistics, vol. 29, no. 5, pp. 1017-1035, 2017.

[8] P. Thomas and A. Chrystal, "Explaining the buy one get one free promotion: the golden ratio as a marketing tool," American Journal of Industrial \& Business Management, vol. 3, no. 8, pp. 655-673, 2013.

[9] K. K. Kim, C. G. Lee, and S. Park, "Dynamic pricing with 'BOGO' promotion in revenue management," International Journal of Production Research, vol. 54, no. 17, pp. 5283-5302, 2015.

[10] A. Bazargan, S. Karray, and S. Zolfaghari, "Buy n times, get one free' loyalty cards: Are they profitable for competing firms? A game theoretic analysis," European Journal of Operational Research, vol. 265, no. 2, pp. 621-630, 2018.

[11] A. Bazargan, S. Zolfaghari, and S. Karray, "Should competing firms offer 'Buy n times, get one free' loyalty programs? A gametheoretic analysis," Journal of the Operational Research Society, pp. 1-20, 2019.

[12] M. Rahimi, V. Ghezavati, and F. Asadi, "A stochastic riskaverse sustainable supply chain network design problem with quantity discount considering multiple sources of uncertainty," Computers \& Industrial Engineering, vol. 130, pp. 430-449, 2019.

[13] M. Khouja, “The single-period (news-vendor) problem: literature review and suggestions for future research," Omega, vol. 27, no. 5, pp. 537-542, 1999.

[14] Y. Qin, R. Wang, A. J. Vakharia, Y. Chen, and M. M. H. Seref, "The newsvendor problem: review and directions for future research," European Journal of Operational Research, vol. 213, no. 2, pp. 361-374, 2011.

[15] W. W. Chang and T.-L. Chen, "The theory of quantity discounts and optimal pricing," International Journal of Economic Theory, vol. 13, no. 2, pp. 185-195, 2017.

[16] B. Avittathur and I. Biswas, "A note on limited clearance sale inventory model," International Journal of Production Economics, vol. 193, pp. 647-653, 2017.

[17] I. Biswas and B. Avittathur, "The price-setting limited clearance sale inventory model," Annals of Operations Research, 2018.

[18] I. Moon, D. K. Yoo, and S. Saha, "The distribution-free newsboy problem with multiple discounts and upgrades," Mathematical Problems in Engineering, vol. 2016, Article ID 2017253, 11 pages, 2016.

[19] S.-P. Chen and Y.-H. Ho, "Analysis of the newsboy problem with fuzzy demands and incremental discounts," International Journal of Production Economics, vol. 129, no. 1, pp. 169-177, 2011.

[20] S.-P. Chen and Y.-H. Ho, "Optimal inventory policy for the fuzzy newsboy problem with quantity discounts," Information Sciences, vol. 228, pp. 75-89, 2013. 
[21] W. Chung, S. Talluri, and R. Narasimhan, "Optimal pricing and inventory strategies with multiple price markdowns over time," European Journal of Operational Research, vol. 243, no. 1, pp. 130-141, 2015.

[22] A. A. Taleizadeh, I. Stojkovska, and D. W. Pentico, "An economic order quantity model with partial backordering and incremental discount," Computers \& Industrial Engineering, vol. 82, pp. 21-32, 2015.

[23] H. Wang, Y. Yu, W. Zhang, and Z. Hua, "Procurement strategies for lost-sales inventory systems with all-units discounts," European Journal of Operational Research, vol. 272, no. 2, pp. 539-548, 2019.

[24] S. Tamjidzad and S. H. Mirmohammadi, "Optimal (r, Q) policy in a stochastic inventory system with limited resource under incremental quantity discount," Computers \& Industrial Engineering, vol. 103, pp. 59-69, 2017.

[25] R. Mohammadivojdan and J. Geunes, "The newsvendor problem with capacitated suppliers and quantity discounts," European Journal of Operational Research, vol. 271, no. 1, pp. 109-119, 2018.

[26] N. Altintas, F. Erhun, and S. Tayur, "Quantity discounts under demand uncertainty," Management Science, vol. 54, no. 4, pp. 777-792, 2008.

[27] J. S. Noh, J. S. Kim, and B. Sarkar, "Stochastic joint replenishment problem with quantity discounts and minimum order constraints," Operational Research, vol. 19, no. 1, pp. 151-178, 2019.

[28] M. Khouja, "The newsboy problem under progressive multiple discounts," European Journal of Operational Research, vol. 84, no. 2, pp. 458-466, 1995.

[29] M. Khouja, "The newsboy problem with multiple discounts offered by suppliers and retailers," Decision Sciences, vol. 27, no. 3, pp. 589-599, 1996.

[30] M. J. Khouja, "Optimal ordering, discounting, and pricing in the single-period problem," International Journal of Production Economics, vol. 65, no. 2, pp. 201-216, 2000.

[31] M. Khouja and A. Mehrez, "A multi-product constrained newsboy problem with progressive multiple discounts," Computers \& Industrial Engineering, vol. 30, no. 1, pp. 95-101, 1996.

[32] T. Chernonog and N. Goldberg, "On the multi-product newsvendor with bounded demand distributions," International Journal of Production Economics, vol. 203, pp. 38-47, 2018.

[33] H. Goto, "Multi-item newsvendor problem with an equality resource constraint," Asia-Pacific Journal of Operational Research, vol. 30, no. 01, p. 1, 2013.

[34] Y. Zhang, W. Zhang, X. Yang, and W. Xu, "A two-product, multi-period nonstationary newsvendor problem with budget constraint," Soft Computing, vol. 23, no. 12, pp. 4277-4287, 2019.

[35] Y. Lu, Y. Chen, M. Song, and X. Yan, "Optimal pricing and inventory control policy with quantity-based price differentiation," Operations Research, vol. 62, no. 3, pp. 512-523, 2014. 


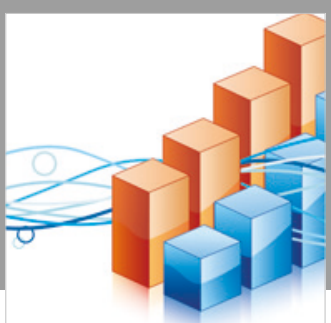

Advances in

Operations Research

\section{-n-m}
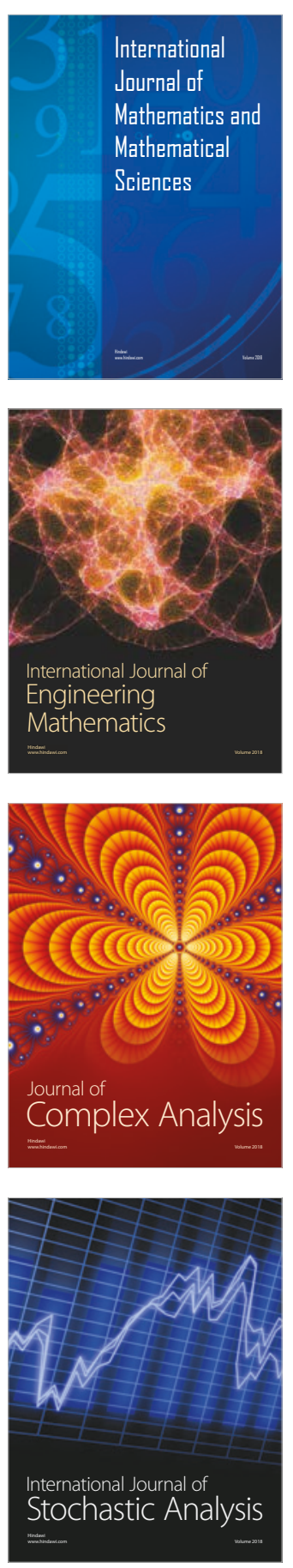
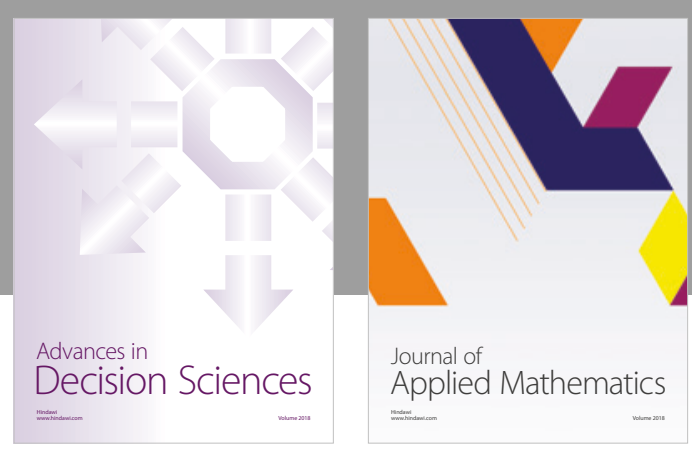

Journal of

Applied Mathematics
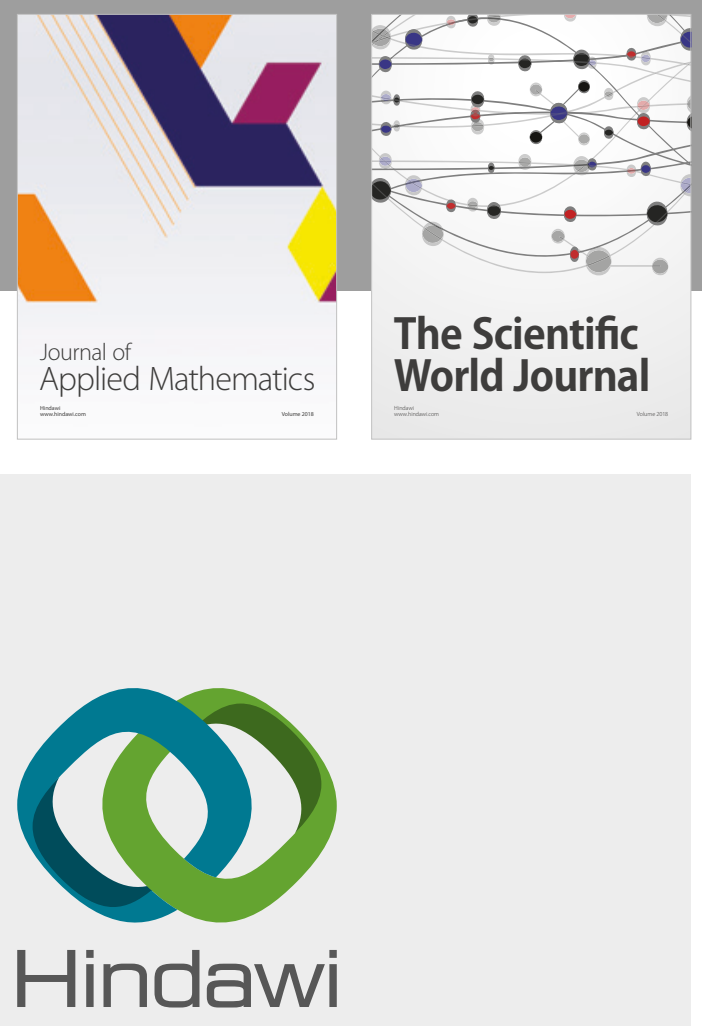

Submit your manuscripts at

www.hindawi.com

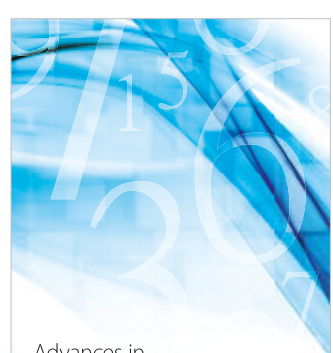

Advances in
Numerical Analysis
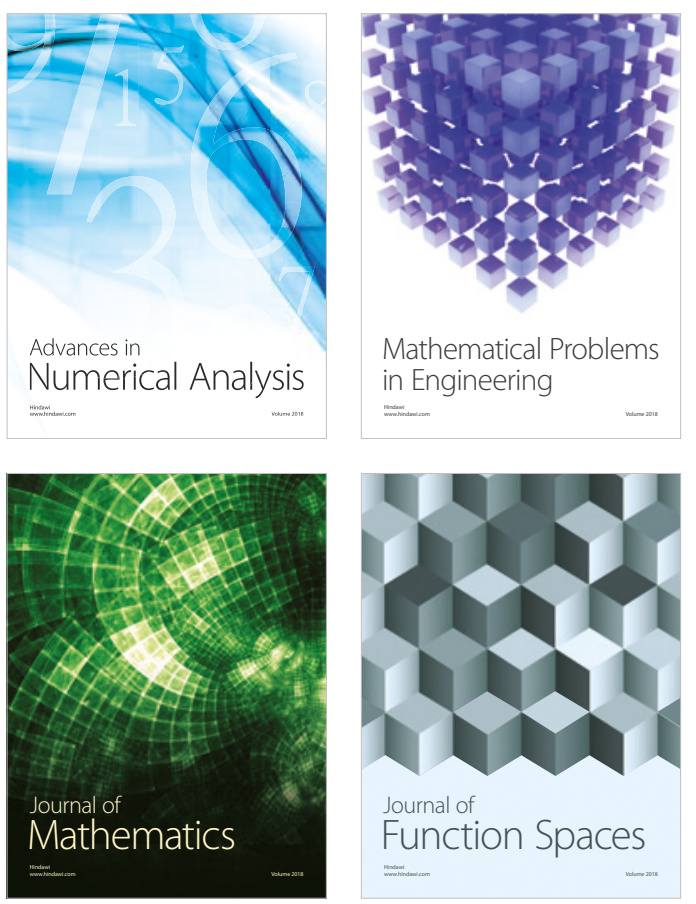

Mathematical Problems in Engineering

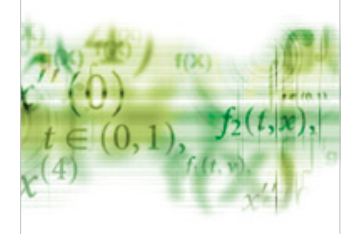

International Journal of

Differential Equations

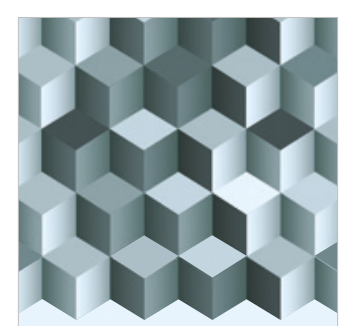

Journal of

Function Spaces

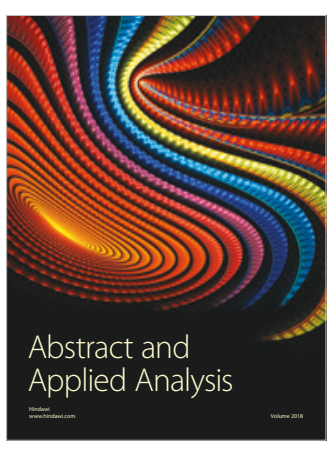

The Scientific

World Journal

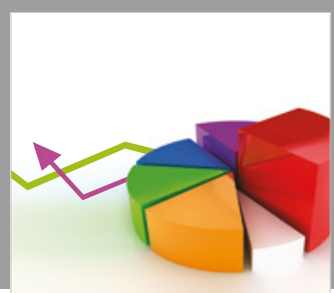

Journal of

Probability and Statistics
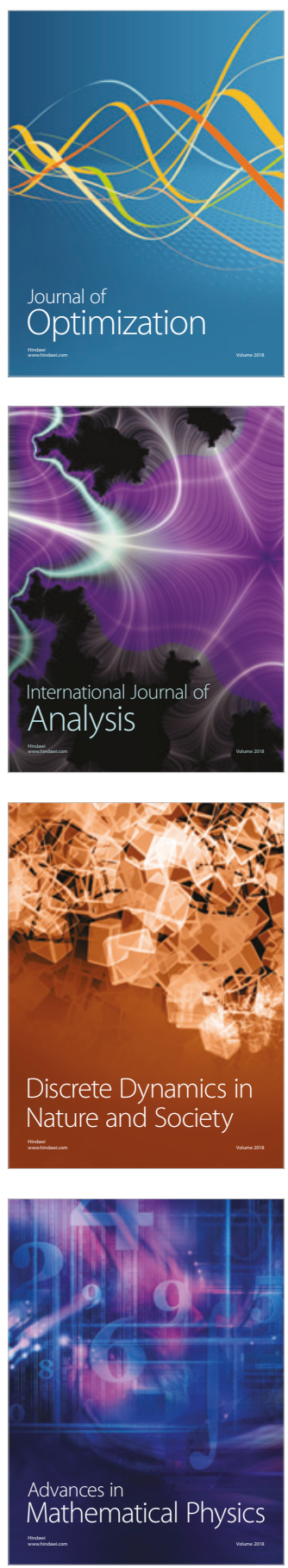